\title{
EDITORIAL
}

\section{Trotting the Radiology road}

\section{Sanjay N Jain}

Editor-in-Chief, Department of Radiology, Prince Aly Khan Hospital, Nesbit Road, Mazgaon, Mumbai - 400010, Maharashtra, India. E-mail: dr.jainsn@gmail.com

\section{Dear colleagues,}

$8^{\text {th }}$ November is the mirror of Radiology across the globe, since it was on this day that the speciality of radiology was born, as Diagnostic Imaging to begin with, with the invention of X-rays in 1895 (118 years ago) by the Father of Diagnostic Radiology, famous German Physicist and Nobel Laureate, Prof. Wilhelm Conrad Roentgen. Radiology and Diagnostic Imaging has traveled a long way so far(1)

When the journey began, Diagnostic Imaging was an assisting modality in medicine, which means to say that we started as imaging technicians. Whenever any other speciality warranted a clearer look into a case on hand, X-rays were pressed into service, based on which an opinion was given on the further modus operandi. This was in vogue for fairly some time, given that a radiologist was mostly doing a back room task, helping out the physician or the surgeon, and was not consulted, or asked, to give any expert opinion or an advice, but was meant to just assist by rolling out X-rays one after the other, based on need.(2)

This may have changed over a period in time, when the radiologist progressed to have been invited to give his observations on the images, as he was qualified to do so. As time progressed, with newer imaging modalities like ultrasound, mammography, color Doppler, computed tomography (CT), magnetic resonance imaging (MRI), and positron emission tomography (PET) scan, Interventional Radiology came into being; the insights into the world of $X$-rays and beyond permeated widely, and these different modalities compelled the need to raise the status of a radiologist, not only confined to be ing invited to give his observations, but, much beyond that, to be requested by the referring specialist for his opinion based on the images read by him. Today, the situation is so advanced that the radiologist can advise as to which modality of imaging is

\begin{tabular}{|l|l|}
\hline \multicolumn{2}{|c|}{ Access this article online } \\
\hline Quick Response Code: & \\
\hline & Website: \\
\hline & www.iji.org \\
\cline { 2 - 3 } & DOI: \\
\hline
\end{tabular}

deemed fit in a given situation, rather than having to go through different modalities one after the other.(3)

Today, Radiology has become a superspeciality in its own right, which offers lot of insights into the world of imaging and helps patients get better care. As a passing reference, Radiation Oncology was also in the ambit of Radiology in the beginnin g, but slowly drifted away with the development of high-end equipment and the cancer patients needing specialized care. With the advent of various imaging modalities, today many cases are being treated with medicines/interventions, which otherwise would have warranted surgery as the only option of cure, though surgery is still well in vogue for cases in need.

Interventional Radiology has changed the entire scenario across the globe today, which has brought the patient and the radiologist in close proximity, as procedures in interventions have been taking the profession to a new high. While all these have been making a lot of news, one fundamental question which keeps running in our minds is that how much is the society aware of the happenings in the field of Radiology, with regard to the services being offered by us and the developments that have been taking place from time to time. In other words, is the society aware about what we do, in particular? The answer is yes, to some extent. A general perception of a radiologist in India was that of a doctor who takes X-rays, when X-ray was the only modality of imaging, but with the advent of other modalities, this perception has changed with the radiologist now being seen as a doctor who reads scans. This is with special emphasis on women, wherein ultrasound is the preferred choice of scan ning different trimesters of pregnancy; thus, the radiologists have this image, particularly in semi-urban cities. In cosmopolitan and metropolitan cities wherein the profession is well connected, different modalities are fairly known to the patients, as they are informed by their referring physician or surgeon.

The situation looks more patient-centric; but how does the society know on a whole? What is being done and what needs to be done? During our year-long rigorous practice, while we may miss out on educating the society, as regards educating about our services, we get an excellent chance annually in November, commemorating Roentgen's X-ray discovery day, beginning with Diagnostic Imaging. 
Radiological societies, especially Radiological Society of North America, European Society of Radiology, etc., to name some premier ones, globally conduct social awareness programs and lead these exercises, given their vast reach. There are several other smaller societies which do their bit to promote the profession in the society. Indian Radiological and Imaging Association (IRIA) has been doing commendable work for over seven decades in educating the society of the services rendered by radiologists at the backdrop of how they have developed. Like last year, this year also, the IRIA has conducted competitive scientific presentations for post graduates in Delhi, in particular, as part of the awareness drive.

The current issue is a mini-symposium on chest radiology. Occupational lung diseases continue to pose a challenge in daily practice with varied manifestations. Highresolution computed tomography (HRCT) forms an important armamentarium in evaluating various aspects of diagnosis and prognosis, as highlighted in one of the articles. Horseshoe lung, along with a pictorial essay on pleural lesions is featured. Neuroradiology section deals with various corpus callosal pathologies, along with encephalocraniocutaneous lipomatosis. The Head and Neck section highlights the role of elastography in benign thyroid nodules. The Interventional section deals with an interesting assessment of direct grasping versus modified snare techniques in retrograde fluoroscopy-guided transurethral exchange of ureteral stents, an emergent technique. Another article focuses on percutaneous transhepatic portal vein stenting in benign non-transplant postoperative portal vein stenosis.

The article on FDG PET-CT deals with current perspectives/ manifestations in lymphomas, including its limitations. The section on breast radiology deals with an article on fat necrosis and relevance in the current era. The abdominal section deals with various articles on endoluminal contrast, placenta accreta, and utility of FIESTA (CISS) sequence. The article on inguinal and femoral canals highlights an important aspect of ultrasonography application, especially for the uninitiated section in radiology residency/practice. The Web-Review section encompasses "Signs in Radiology."

As we continue to walk on the radiology road, the source of our bread and butter, we are engulfed with changes that make us look into ourselves in pursuit of searching answers for two very fundamental questions: How do we constantly learn and improve our knowledge base for the best patient care? How do we keep the society abreast of our speciality on a continued basis? The search for answers of these selfevolving questions continues.

\section{Suggested Readings}

1. Andrews JR: Planigraphy I. Introduction and History. Am Journ Roentgenol, 1936;36:575-87.

2. Brecher R, Brucher E: The rays. Williams \& Wilkins Co, Baltimore, 1969.

3. Hendee W: Cross sectional medical imaging: A history. Radiographics 1989;9:1155-80. 